\title{
Treatment in the community in the absence of consent
}

\author{
J. A. T. Dyer
}

Because of the nature of some mental illiness, care and compulsion in poychiatiry are not always antithefical. However, it is no longer acceptable to link compulsory treatment almost exclusively to compulsory hospltalisation. Treatment should occur in the least restrictive environment possible. This paper looks of experience of extended leave of absence in Scottand, and in England and Wales belore 1986, at the recent ovidence for an increased risk of violence and homicide in schizophrenia and the danger of a backlash against community care if it is percelved as unscate, and makes suggestions in relation to research and to provision for treatment in the community in the absence of consent.

Government in both England and Wales and Scotland is beginning to recognise the need to revise the Mental Health Acts of 1983 and 1984. The College Registrar has made it clear that the College now wishes to think about what evidence it might wish to put forward in discussions of new Mental Health Acts. An important element of such discussions should be a provision to allow treatment in the community in the absence of consent.

The detention and treatment provisions in the 1983 and 1984 Mental Health Acts, based as they are on the preceding 1959 and 1960 Acts, belong to an earlier era. They are fixated on buildings rather than services and are not flexible in allowing treatment to be tailored to the needs of the individual. Involuntary hospitalisation and treatment are bound together (with the exception of treatment on leave of absence, now restricted to 12 months). This fixed outcome approach is not acceptable today.

\section{Least restrictive intervention}

Mental health policy is increasingly based on the ethical principle of least restrictive intervention. It is anachronistic to insist that everyone requiring treatment in the absence of their consent needs to be detained in hospital in order to receive such treatment. The previous Mental Health Acts accepted the need for involuntary treatment, a need which is based on the reality of severe mental disorder. Some people with psychotic illness lack insight into their condition so that they do not know that they are ill, and therefore they cannot make considered judgements about accepting or refusing treatment. The right to autonomy in such situations has to be balanced against the right to receive treatment when unable to make a decision about it, and to be protected from inflicting harm on self or others, as well as the right of other people to be protected.

The need for involuntary treatment is not an alternative to the need to educate and support people towards better acceptance of care and treatment, and the need for proper resources and comprehensive services. These issues are often falsely polarised. There is a need for better educational measures and better resources, with more assertive outreach services, and cooperation with treatment will be improved by development of medication with fewer unpleasant side-effects. But even if everything else were to be supplied there would remain a further necessary ingredient for a very small number of people, namely treatment in the community in the absence of consent. For some reason, those who accept the principle of involuntary treatment in hospital argue strongly against it in the community, even although being in the community as opposed to hospital is a situation of lesser restriction.

\section{Experience with leave of absence}

Those who argue against involuntary treatment in the community conjure up a picture of hit squads of community psychiatric nurses descending on people's houses, pinning them down in their living rooms and administering depot injections. This is not, however, the experience in Scotland where compulsory treatment in the community was available until 1996 in the form of leave of absence of unrestricted duration. At the end of 1994 in Scotland there were 129 people who had been on leave of absence for over 12 months. Seventeen of these had been on leave of absence for over three years and five on leave of absence for over four years. A research study involving the Mental Welfare Commission (Atkinson et al, 1997) asked Scottish consultants their 
reasons for extending leave of absence beyond six months and the most common reasons were 'threat of stopping medication' and 'lack of insight'. The most common reason for recall to hospital from leave of absence was 'stopping medication'. The overwhelming experience in Scotland is that when people know that there is a legal authority for their medical treatment, they accept it. This, of course, is not true for everyone; for some patients who go on resisting treatment a decision has to be made between giving up the compulsory provision, or recalling the patient to hospital. Repeated forceful administration of medication does not happen.

Extended leave of absence was also used in England prior to 1986 . When a sample of such patients was compared to a control group (Sensky et al, 1991) they more commonly had a history of recent dangerousness and non-compliance with treatment. Use of extended leave improved treatment compliance, reduced time spent in hospital and reduced levels of dangerousness. Little is known about current use of Section 17 leave of absence in England and Wales. There is said to be uncertainty over whether beds need to be kept or not, and difficulties over benefit payments. Perhaps the Mental Health Act Commission could carry out a study.

The Mental Health (Patients in the Community) Act 1995 does not offer a satisfactory alternative to leave of absence beyond 12 months in Scotland, or extension to such leave of absence in England and Wales, because it lacks a power to insist on treatment in the community.

\section{Violence and public support of community care}

The main argument for treatment in the community without consent is in the interests of patients too ill to make an informed choice about treatment, so that serious decline in health can be prevented. But there is also a wider argument. Community care depends upon public acceptance. If the public perception becomes that community care is unsafe, there could be a backlash which would sweep people back into institutional care, including a majority who do not pose a threat to themselves or to other people. The issue of a risk of violence associated with serious illness such as schizophrenia requires a realistic appraisal. There has been a view in recent decades that people with schizophrenia have no higher risk of violent offending or homicide than the general population. This view was probably emphasised by early enthusiasts about community care, seeking to reassure the public and to counteract the exaggerations of the media.
Recent epidemiological research in Europe and the USA using more rigorous methodology than earlier work has forced a revision of the association between violent crime and serious mental disorder. Considerably increased rates of conviction for violent offences have been found in Sweden in people with psychosis in a birth cohort study (Hodgins, 1992), and in discharged patients with schizophrenia compared to the general population (Lindqvist \& Allebeck, 1990). In Camberwell, patients with DSM-III-R schizophrenia had three times the risk of conviction for violence compared with other patients (Wessely et al, 1994). Not all violence associated with schizophrenia appears in criminal conviction statistics. Humphries et al (1992) showed that among patients in the Northwick Park Study of First Episodes of Schizophrenia, one-fifth behaved in a way threatening to the lives of others prior to admission to hospital in their first episode.

There is thus good evidence that serious mental illness such as schizophrenia is associated with a significant increase in the risk of violent offending, although it does not make much contribution to the overall violent crime figures. Some recent studies on homicide associated with mental illness have also added to earlier information. In 1984 Taylor \& Gunn published a study of remand prisoners in Brixton and found that $8.2 \%$ of those charged with homicide suffered from schizophrenia. Putting their findings together with an earlier study in Germany by Hafner \& Boker (1982) they estimated that in about 5-10\% of homicides the perpetrator suffered from schizophrenia. A study of homicides in Finland (Eronen et al, 1996) found that homicide risk was increased eightfold in men with schizophrenia.

Studying the available data it seems reasonable to conclude that people with schizophrenia have approximately 10 times the risk of homicide of the general population and that such homicides account for approximately $5 \%$ of all homicides. (This has to be viewed in perspective of course 95\% of homicides are committed by people without schizophrenia.) One would therefore expect about 35 homicides in England and Wales annually to be committed by people with schizophrenia, and in Scotland three to four per year.

Such calculations would be broadly consistent with the Confidential Enquiry into Homicides by Mentally Ill People in England and Wales set up by the Department of Health in collaboration with the Royal College of Psychiatrists (1996). This suggested that just under 20 homicides per year in the early 1990s were carried out by people who had had psychiatric contact within the previous 12 months. In $41 \%$ of cases in the community studied (15 out of 36 cases). 
problems in administration of medication were recorded. The discussion noted that "probably the most commonly stated cause of failure of continuing care was that treatment had been offered, but not accepted or continued". Evidence is also beginning to emerge from the large McArthur Violent Risk Assessment Study set up in the United States (Anonymous, 1996). Factors associated with a greater risk of violence include refusal to continue treatment, inability to function effectively in daily life, several changes of residence and pervasive delusions.

Community care which lacks realistic measures to deal with the small core of patients who present such risks will not go on being accepted by the public.

\section{European convention on human rights}

In arguing against community treatment powers, the Government has invoked Article 5 of the European Convention on Human Rights. Article 5 says "Everyone has the right to liberty and security of person. No-one shall be deprived of his liberty save in the following cases and in accordance with a procedure prescribed by law:...(e) the lawful detention of persons... of unsound mind...".

This was elaborated in the case of Winterwerp v. the Netherlands in 1979 (ECHR, Ser. A, No. 33, 24 October 1979) and the so called Winterwerp requirements state that (1) true mental disorder must be established by objective medical expertise; (2) the mental disorder must be of a kind or degree which warrants compulsory confinement: (3) continued detention should be determined on the persistence of the disorder.

This is really to do with detention or confinement rather than treatment but becomes relevant if one might wish to have the possibility of an admission to hospital as a sanction against failure to take required treatment in the community.

It would be useful for the College to get advice from an independent expert in international law in relation to the European Convention on Human Rights. It is probably not an insurmountable obstacle to a community treatment order. It may be that Scotland is on stronger ground here, however, since detention in Scotland has to be approved by an independent judicial figure in the form of the sheriff. Although not the ideal solution, it may be that compulsory treatment in the community might have to be in the form of a sort of conditional discharge following an involuntary admission to hospital. Taking medication would then be a condition of the discharge, and would make the concept of readmission with failure to comply easier to justify, especially if the original detention was approved by a court. What would be preferable, however, would be a community treatment order approved by a court or tribunal without the necessity for a prior admission to hospital, but with a power to admit to hospital in the event of non-cooperation with required treatment. The criteria for the order would be similar to those existing at present for compulsory detention with the additions that there should have to be evidence that the person has responded to treatment in the past, has tended not to take treatment voluntarily in the past, and when ill has put at risk their own health or safety or the safety of other people. Such an order should be subject to regular review by a tribunal or sheriff.

\section{Conclusions}

It is therefore proposed that the Royal College of Psychiatrists, in reviewing what is required for a revision of the 1983 and 1984 Mental Health Acts, re-examines the need for an order ensuring treatment in the community in the absence of consent. In so doing, it would be useful to get independent expert advice on international law in relation to this issue.

The College Research Unit and the Mental Health Act Commission might also consider studying current use of leave of absence in England and Wales and attendant problems and also testing views of consultant psychiatrists on the need for a new kind of order suggested here.

Care and compulsion in psychiatry are not always antithetical. For the most severely ill patients, they can go hand in hand in providing humane care in the best interests of patients, balancing a right to liberty with a right in a civilised society not to be denied treatment when the patient is too ill to make his or her own decision - treatment given in the least restrictive environment possible.

\section{Acknowledgement}

The contents of this paper have been endorsed by the Executive Committee of the Social, Community and Rehabilitation Section and I am grateful to members for comments.

\section{References}

ANONYMOUS (1996) Violence may be predicted amongst psychiatric patients. British Medical Journal, 313, 318.

ATKinson, J. M., GILMOUR, W. H., DYER, J. A. T., et al (1997) Consultants' views of Leave of Absence and Community Care Orders in Scotland. Psychiatric Bulletin, 21, 9194.

ERonen, M., Hakola, P. \& ThlHonen, J. (1996) Menta disorders and homicidal behaviour in Finland. Archives of General Psychiatry. 63, 497-501. 
HAFNER, H. \& BOKER, W. (1982) Crimes of Violence by Mentally Abnormal Offenders. The Psychiatric Epidemiology in the Federal German Republic. Cambridge: Cambridge University Press.

HoDGins, S. (1992) Mental disorder, intellectual deficiency and crime: evidence from a birth cohort. Archives of General Psychiatry, 49, 476-483.

HUMPHRIES, M. S., JohNSTONE, E. C., MACMiLlan, J. F., et al (1992) Dangerous behaviour preceding first admissions for schizophrenia. British Joumal of Psychiatry, 161. 501-505.

LINDQVisT, P. \& ALLEBECK. P. (1990) Schizophrenia and crime: a longitudinal study of 644 schizophrenics in Stockholm. British Journal of Psychiatry, 157, 345-350.

ROYAL COLLEGE OF PSYCHIATRISTS (1996) Report of the Confidential Enquiry into Suicides and Homicides by Mentally II People. London: Royal College of Psychiatrists.

Sensky, T., Hughes, T. \& HiRSCH, S. (1991) Compulsory psychiatric treatment in the community. I: A controlled study of compulsory community treatment with extended leave under the Mental Health Act: special characteristics of patients treated and impact of treatment. British Journal of Psychiatry, 158, 792-799.

TAYLOR, P. J. \& GUNN, J. (1984) Violence and Psychosis. I: risk of violence among psychotic men. British Medical Journal, 288, 11945-1949.

Wessely, S., Castle, D., Douglas, A. J., et al (1994) The criminal careers of incident cases of schizophrenia. Psychological Medicine, 24, 483-502.

J. A. T. Dyer, Ex-Chairman, Social Community and Rehabilitation Section, Royal College of Psychiatrists and Director, Mental Welfare Commission for Scotland, Argyle House, Floor K, Lady Lawson Street, Edinburgh EH3 9SH

\title{
Gaskell Academic Series
}

\section{Interpersonal Factors in Origin and Course of Affective Disorders}

\author{
Edited by Ch. Mundt, M.J. Goldstein, K. Hahlweg and P. Fiedler \\ with the assistance of Hugh Freeman
}

This detailed overview of the latest research on affective disorders brings together authors of international background and repute. Both a theoretical and practical approach to the origin and course of affective disorders is presented, covering specific problems and settings. The principal areas covered are: personality factors, risk and course; social support; marital and family interaction; and intervention.

\section{$\bullet £ 30.00 \bullet 368$ pp. • Hardback • $1996 \bullet$ ISBN 0902241907 \\ Available from good bookshops and from the Publications Department, Royal College of Psychiatrists, 17 Belgrave Square, London SW1X 8PG (Tel. 0171-235 2351, extension 146)}

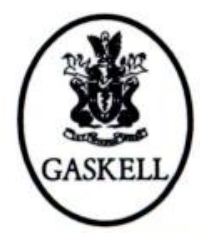

